This is a post-peer-review, pre-copyedit version of an article published in European Food Research and Technology. The final authenticated version is available online at: https:// doi.org/10.1007/s00217-016-2807-9 


\section{Assessing wine sensory attributes using Vis/NIR}

José Antonio Cayuela, 1 ,

Phone +34 954611550

Email jacayuela@ig.csic.es

Belén Puertas, 2

Emma Cantos-Villar, ${ }^{2}$

${ }^{1}$ CSIC-IG, Fisilogía y Tecnología de Productos Vegetales, Seville, Spain

2 Instituto de Investigación y Formación Agraria y Pesquera (IFAPA) Rancho de la Merced, Ctra Trebujena, km 2.1, 11471 Jerez de la Frontera, Spain

\section{Abstract}

The quality of wine involves the presence and intensity of many flavors and nuances. The assessment by tasting panels of the sensory quality of wine and by measuring the intensity of their attributes or defects is more difficult than assessing the global score of wine quality, which is a single value for each wine. This research focused on the feasibility of the visible and near-infrared spectroscopy for assessing wine sensory attributes. Predictive models of sensory attributes such as positive and negative for red and white wines have been developed, based on their spectra and reference values from a specialized tasting panel. The results indicate that the technique is feasible for predicting some of the most characteristic sensory attributes of red and white wines such as Flavor intensity, Astringency, Color intensity, Length, Persistency, Pleasantness and Balance. Their correlation coefficients of validations were about 0.9 in most cases. The technique was also suitable for predicting some important defects such as Oxidation, Unclean, Ethyl acetate and Acetic acid. The main potential use of this technique is for contrasting or confirming the assessment of wine for the positive and negative sensory attributes, determined by the sensory analysis of tasting panels. This can be particularly useful in cases where there is discrepancy in the assessments of a sensory panel. It is reasonable to consider the possibility of tuning the technique for detection in routine analysis of some negative attributes. 


\section{Keywords}

Attributes

Sensory analysis

Tasting panel

Vis/NIR

Wine

\section{Abbreviations}

CSIC Spanish Council for Scientific Research

IFAPA Institute Research and Training Agricultural and Fisheries

MN Mean normalization

NIRS Near-infrared spectroscopy

PC Principal components

$R_{\mathrm{C}} \quad$ Coefficient of calibration

$r$

Correlation coefficient between the analyzed and predicted values in the external validation exercises

$R_{\mathrm{CV}} \quad$ Coefficient of cross-validation

RPD Residual predictive deviation

SD Standard deviation

SEC Standard error of calibration

SEP Standard error of performance

Vis/NIR Visible and near infrared

Vis/NIRS Visible and near-infrared spectroscopy

\section{Introduction}

\section{Wine sensory attributes}

The quality of wine involves the presence and intensity of many flavors and nuances. The sensory evaluation of wine quality is very important, since the purpose of its consumption is hedonic. Therefore, among the chemosensory sensations and their combinations, intensity and harmony are major components in the quality of the product.

During the elaboration of wine, sensory defects may appear. The flavor deviations are subjective and require standardization for their variety or geographical origin. Besides, there is a wide range of sensory spoilage in different winemaking techniques, each with specific characteristics and causes. The main agents involved in the wine's alteration are bacteria and yeast, but 
chemical and physical changes may also produce some defects. It is very interesting to have a fast and cheap method able to verify the absence of defect in wines.

\section{Assessing wine sensory quality}

The assessment of wine sensory quality is difficult, because it involves many signs $[1,2]$. Describing the sensations produced by the produce is complex, and even more to quantify them. The same occurs for the identification and quantification of defects. The variability of the sensitivity of the tasters is one of the problems in sensory analysis, since various judges can perceive the same stimulus in a different way. In addition, depending on several causes such as the environment, concentration, tiredness, hunger and others, the same judge can perceive the same stimulus as mismatched at different moments. To assure the accuracy of the results, sensory analysis is carried out by qualified judges who have been previously trained. To overcome the difficulties of sensory analysis, several strategies have been suggested such as improving training through visual and olfactory mental imagery [3] or defining precisely the palate cleansers for specific purposes [4].

Moreover, it is necessary not only to describe sensory descriptors, but also to quantify them. Still traces of some volatile compounds may produce aromas and flavors in wine [5]. However, some of these molecules are difficult to detect by chemical analysis. Frequently, the wine flavors do not come from a unique compound but a complex mix of several compounds [6]. Despite great improvements, the more sophisticated techniques are not reliable enough for the control of wine quality $[3,4]$. Both the quantity and interaction among compounds are key factors of the sensory attributes. For this reason, beyond the analysis of volatile compounds, sensory analysis is essential in wine quality studies, despite its difficulties.

\section{Near-infrared spectroscopy}

Near-infrared spectroscopy (NIRS) can provide solutions to the abovementioned difficulties, since the spectral information may better integrate the physicochemical properties of matter than several or individual chemical markers. This can be one of the main advantages of NIRS regarding electronic noses and tongues. This idea agrees with the conclusions of a comparative study which showed NIRS as the most powerful analytical technique, whereas the artificial nose seemed to be less informative, it is the most expensive [7]. NIRS has been proven useful for characterizing quality in various foods. Developing predictive models is usually based on multivariate analysis methods. Different studies reported good NIRS predictions of sensory features in different foods 
such as cheese $[8,9,10]$, fresh meat $[11,12,13]$, ham [14] and several horticultural products $[15,16,17,18]$. The possibility of sensory characterizing wine by NIRS has also been reported. However, the information available is rather scarce, especially on using the panel test for assessing the reference values of specific sensory attributes. The same occurs with the detection of wine defects. The correlation between the sensory attributes of wine and its Vis/NIR spectra is reported only from research with Riesling and Chardonnay white wines [19]. An additional study was conducted to correlate the quality score values of wines, assessed by a tester panel, with their spectrum Vis/NIR [20]. Assessing the wine quality score, which is a single value for each wine, is different from gauging the intensity of each of their attributes or defects. It must be highlighted that this last study has not been reported for red wines, up to date. The possibility of measuring sensory attributes of wines by combining Vis/NIRS with mass spectrometry has also been reported [2].

Besides, measuring the intensity of certain defects for which is advisable rejecting a wine can be useful for the industry. Vis/NIRS could predict defects such as oxidation, grubby, acetic or acetate in a multi-parameter wasy, although there are no reports for these purposes.

AQ1

The goal of this study was to explore the feasibility of assessing sensory attributes and detecting sensory defects of red and white wines by Vis/NIRS. The reference sensory analysis was carried out by a panel of expert tasters.

\section{Materials and methods}

\section{Sensory analysis}

A quantitative descriptive analysis of wines was planned and carried out according to Spanish regulation UNE-87-017-92 [21], which corresponds to international norm ISO 6564:1985. It describes the methodology to establish the flavor profile. The consensus method was selected as the methodology to develop this analysis.

Wines sensory analyses were performed at IFAPA Rancho de la Merced (Junta de Andalucía, Jerez) by a panel of 8 judges ( 6 women and 2 men), all with extensive experience in wine tasting. In the first phase, the qualitative and quantitative criteria were established. The most important descriptors were determined by the judges by tasting different wines. The relationships and redundancies among the preselected attributes were discussed in each session until final selection. Then, the panel leader proposed the definitions of each of the selected attributes. Habitual wine terminology was used. Selected aroma 
descriptors were similar to those of the wine aroma wheel [22, 23, 24]. Once the attributes or descriptors were selected and defined, panelists were trained to quantify using structured numerical scales. The attributes' scales ranged from absence of sensation or no perception to very high or intense perception, which were scored from 0 to 10 points. A final global evaluation of each wine was expressed as Global Value using the values 1-2 for very bad wines, 3-4 for bad, 5-6 for acceptable, 7-8 for good, and 9-10 for very good.

In each sensory session, the panel evaluated 6 or 7 wines in randomized blocks. Each wine sample consisted of $50 \mathrm{~mL}$ of wine at room temperature $\left(20^{\circ} \mathrm{C}\right)$ in a 190-mL ISO clear glass covered with a watch glass. All tasting sessions were always held in the same lighting conditions, at 13:30 $\mathrm{h}$ in the tasting room of the IFAPA Rancho de la Merced. The scores of the sensory attributes are detailed in Table 1.

\section{Table 1}

Sensory attributes assessed by the panel of judges

\begin{tabular}{|c|c|}
\hline Attribute & Description \\
\hline \multicolumn{2}{|l|}{ Positive } \\
\hline $\begin{array}{l}\text { Color } \\
\text { intensity }\end{array}$ & $\begin{array}{l}\text { Expresses the degree of color strength, depending on the lengths of } \\
\text { reflected visible wavelengths, and overall impression received }\end{array}$ \\
\hline $\begin{array}{l}\text { Flavor } \\
\text { intensity }\end{array}$ & Expresses the degree of flavor strength \\
\hline Tone & $\begin{array}{l}\text { Distinguish one color from another, referring to the lengths of } \\
\text { reflected visible wavelengths. Indicates possible oxidation process }\end{array}$ \\
\hline Length & Express a sensation of broad which fills the mouth \\
\hline Astringency & Tactile quality caused by phenols, mainly by tannins \\
\hline Persistency & $\begin{array}{l}\text { Wines leaving a flavor mark that lingers in the mouth. The } \\
\text { persistency is usually considered low when its duration is less than } \\
2 \mathrm{~s} \text {, average when it is from } 2 \text { to } 5 \mathrm{~s} \text {, high of } 5-8 \mathrm{~s} \text {, and high above } 8\end{array}$ \\
\hline Fruity & $\begin{array}{l}\text { Flavor from ripe and fresh grape that has not been transformed during } \\
\text { fermentation. It also applies to remember of other fruits, such as red } \\
\text { fruit, citrus and tropical }\end{array}$ \\
\hline Pleasantness & $\begin{array}{l}\text { A wine which produces pleasure, for its sensory attributes as a whole } \\
\text { or by one of them }\end{array}$ \\
\hline Balance & $\begin{array}{l}\text { Proper proportion of each desirable element, without any individual } \\
\text { dominance. It is related to the global sensation, but it is especially } \\
\text { focused on the relation among acidity, astringency, alcoholic } \\
\text { sensation and body }\end{array}$ \\
\hline \multicolumn{2}{|l|}{ Negative } \\
\hline Bitterness & A wine is an unpleasant mouth feel, pointing defects \\
\hline
\end{tabular}




\begin{tabular}{|c|c|}
\hline Oxidation & The unpleasant taste from wines having suffered excessive contact \\
\hline Attribute & Description \\
\hline Reduction & Reminds sulfur odor \\
\hline Acidity & $\begin{array}{l}\text { Wine with the predominantly acidic flavor due to natural acids from } \\
\text { grape or fermentation. Acid moderate is positive, while acid very } \\
\text { high or very low are defects }\end{array}$ \\
\hline Yeast & Remembers the flavor produced from yeast \\
\hline Acetic acid & Remembers vinegar flavor \\
\hline $\begin{array}{l}\text { Ethyl } \\
\text { acetate }\end{array}$ & Reminds glue flavor, from harmful fermentation \\
\hline Herbaceous & Grass aroma from insufficient maturity of the grapes \\
\hline Unclean & Reminds rotten egg odor \\
\hline
\end{tabular}

\section{Wines}

Samples of the red and white wines analyzed were obtained mainly from winemaking assays conducted in the Rancho de la Merced center (IFAPA, Junta de Andalucía). The wines come from grapes of 13 varieties of red and 12 white. A wide range of wines from different research trials were used. This experimental factor was used for expanding the range of the sensory features tested, each wine sample being different. Moreover, 7 red and 6 white commercial wines were used for the same purpose. These commercial wines belonged to the protected geographical indication 'Tierra de Cádiz.' All noncommercial samples were from different winemaking trials using varieties grown in the Rancho de la Merced. The study was conducted with a total set of 180 samples for red wines, and 130 for white wines. The vine varieties used are shown in Table 2 .

\section{Table 2}

Vine varieties used in winemaking trials

\begin{tabular}{|c|c|c|c|}
\hline \multicolumn{2}{|l|}{ White wines } & \multicolumn{2}{|l|}{ Red wines } \\
\hline Variety & $N$ & Variety & $N$ \\
\hline \multicolumn{4}{|l|}{ Season I } \\
\hline Colombard & 2 & Blasco & 2 \\
\hline Chardonnay & 18 & Cabernet sauvignon & 2 \\
\hline Muscat of Alexandria & 2 & Corchera & 6 \\
\hline
\end{tabular}




\begin{tabular}{|c|c|c|c|}
\hline $\begin{array}{l}\text { White wines } \\
\text { Moscatel de Frontignan }\end{array}$ & 2 & $\begin{array}{l}\text { Red wines } \\
\text { Merlot }\end{array}$ & 2 \\
\hline $\begin{array}{l}\text { Kariety } \\
\text { Palommo fino }\end{array}$ & 18 & $\begin{array}{l}\text { Yariety } \\
\text { Pastora }\end{array}$ & 2 \\
\hline Riesling & 2 & Prieto picudo & 2 \\
\hline Sauvignon blanc & 18 & Syrah & 28 \\
\hline Gewürztraminer & 2 & Tempranillo & 24 \\
\hline Vijiriega & 2 & Tintilla de Rota & 24 \\
\hline \multicolumn{4}{|l|}{ Season II } \\
\hline Chardonnay & 6 & Carmenere & 2 \\
\hline Indiana & 2 & Corchera & 2 \\
\hline Muscat of Alexandria & 1 & Malbec & 2 \\
\hline Palomino fino & 20 & Pastora & 2 \\
\hline Pedro Ximénez & 4 & Syrah & 52 \\
\hline Sauvignon blanc & 26 & Tannat & 2 \\
\hline Gewürztraminer & 1 & Tempranillo & 12 \\
\hline Vermentino & 2 & Zinfandel & 2 \\
\hline Vijiriega & 2 & Tintilla de Rota & 12 \\
\hline
\end{tabular}

\section{Spectra acquisition}

After sensory analysis, the wine samples were transported by urgent messenger service to the Instituto de la Grasa (CSIC, Seville), where the wine spectra were registered.

The spectrum of every sample was acquired by using a $350-$ to $2500-\mathrm{nm}$ spectrophotometer Labspec (Analytical Spectral Devices Inc., Boulder). The instrument control software was Indico Pro, from the same company.

Labspec is a Visible/NIR spectrometer equipped with three detectors. The detector for the visible is a fixed reflective holographic diode array with a sensitivity of 512 pixels, covering from 350 to $1000 \mathrm{~nm}$. The wavelength range of 1000-1800 $\mathrm{nm}$ is covered by a holographic fast scanner InGaAs detector cooled at $-25{ }^{\circ} \mathrm{C}$. The same equipment coupled with a high order blocking filter 
works for the 1800- to $2500-\mathrm{nm}$ range. The instrument has internal shutters and automatic offset correction, with a scanning speed of $100 \mathrm{~ms}$.

The transmittance spectra were recorded from each sample directly from the wines, without any other treatment and two repetitions. A Hellma quartz spectrophotometric cuvette with a $5-\mathrm{mm}$ path length held the samples, while their average spectrum is acquired. The whole spectrum Vis/NIRS (350$2500 \mathrm{~nm}$ ) was registered, each spectral variable corresponding to a $2-\mathrm{nm}$ interval. The registering was configured for 50 spectra in continuous mode. Indico Pro software (Analytical Spectral Devices Inc., Boulder) was used for this purpose. The acquisition processing time for each sample is less than a minute, all steps included. The reference baseline was taken with the air contained in the spectrophotometric cuvette. Each sample was registered with two replicates. The samples temperature for registering their spectra was $23{ }^{\circ} \mathrm{C}$, ensuring this by using a thermostatic bath.

\section{Chemometrics and model development}

The predictive models were developed by Partial Least Squares using the Unscrambler 9.7 (CAMO Software AS, Norway). The transmittance spectral data were transformed to absorbance. Various alternative data processing before model calibration were assessed, including normalization by the mean $(\mathrm{MN})$, as well as first and second derivatives of the same data. The number of principal components of the calibrations (PC) was set by successive approaches, usually in the second calibration test.

The spectral variables which contribute to the predictive models for each attribute or defect were selected with the Unscrambler 9.7 by performing several successive cycles. In these, the wavelengths whose contribution to the analyzed feature is closer to zero are eliminated. Variable selection ended in the last cycle that improved the statistical coefficient of cross-validation $\left(R_{\mathrm{CV}}\right)$. Assessing the model's fitness was according to its standard error of calibration (SEC) and the closeness between their coefficient of calibration $\left(R_{\mathrm{C}}\right)$ and $R_{\mathrm{CV}}$.

Two calibrations for each attribute or defect of red wines were built from different set samples, corresponding to two seasons (I and II). The performance with each calibration was compared. One-third of the total samples in each calibration were set aside for validating, as detailed below. The same tests were made with white wines for calibrating and validating, although the sets were smaller. Some samples with reference values repetitive were separated from the calibrations and validations, as hereinafter discussed. 
Calibration fit was assessed previously to external validation, by the agreement between $R_{\mathrm{CV}}$ and $R_{\mathrm{C}}$ and by its $\mathrm{SEC}$.

\section{Validation}

The calibration models were assessed through external validation tests. These consist of predicting the attributes intensities in a previously reserved sample set. Assessing the model performance was mainly according the $r$ from the external validation exercises. This matches to the correlation coefficient of the simple linear regression between the analyzed and predicted values. The residual predictive deviation (RPD) was also considered. According Williams and Sobering [25], the RPD is the ratio of the SD of the reference data from the validation set to the standard error of performance (SEP). The statistic RPD was used to aid interpretation since it is essentially the same statistic $r$ previously defined [26].

\section{Results}

\section{Sensory analysis}

The statistical data of the red wine attributes, from the calibration and validation sets, are included in Table 3, and the same for white wines are shown in Table 4. As it can be observed from the ranges and standard deviations, the attributes of the wines had broad diversity, which is necessary for basing the robustness of the calibration.

Table 3

Population statistics from the calibration and validation sets of red wines

\begin{tabular}{|c|c|c|c|c|c|c|c|c|c|}
\hline \multirow{2}{*}{ Attributes } & \multirow{2}{*}{ Set } & \multicolumn{4}{|c|}{ Calibration } & \multicolumn{4}{|c|}{ Validation } \\
\hline & & $N$ & $\bar{x}$ & $\sigma$ & Range & $N$ & $\bar{x}$ & $\sigma$ & Range \\
\hline
\end{tabular}

Positive

\begin{tabular}{|l|l|l|l|l|l|l|l|l|l|}
\hline \multirow{2}{*}{ Flavor intensity } & I & 92 & 5.5 & 1.93 & $0.4-8.2$ & 22 & 5.7 & 1.86 & $0.7-7.6$ \\
\hline \multirow{2}{*}{ Color intensity } & II & 115 & 5.8 & 1.84 & $0.4-8.0$ & 36 & 5.4 & 2.00 & $0.5-8.2$ \\
\hline \multirow{2}{*}{ Length } & I & 90 & 7.2 & 1.14 & $2.1-9.0$ & 21 & 7.2 & 1.17 & $3.7-8.2$ \\
\hline & II & 111 & 7.4 & 0.98 & $3.3-9.0$ & 39 & 7.3 & 1.27 & $2.1-8.9$ \\
\hline & I & 93 & 5.9 & 0.80 & $3.9-7.2$ & 22 & 5.9 & 0.95 & $4.0-7.8$ \\
\hline & II & 110 & 5.9 & 0.74 & $3.9-7.2$ & 60 & 6.0 & 0.83 & $3.9-7.6$ \\
\hline & I & 90 & 5.8 & 0.92 & $2.7-7.5$ & 22 & 5.9 & 0.99 & $3.3-7.8$ \\
\hline
\end{tabular}


Persistency

\begin{tabular}{|c|c|c|c|c|c|c|c|c|c|}
\hline Attributes & Set & \multicolumn{3}{|c|}{$\begin{array}{l}\text { Calibration } \\
115 \quad 6.0\end{array} \quad 0.84$} & \multirow{2}{*}{$\begin{array}{l}2.7-7.8 \\
\text { Range } \\
1.6-8.0\end{array}$} & \multicolumn{3}{|c|}{$\begin{array}{l}\text { Validation } \\
38 \\
5.8\end{array} 0.94$} & \multirow{2}{*}{$\begin{array}{l}2.9-7.1 \\
\text { Range } \\
2.5-8.0\end{array}$} \\
\hline \multirow{2}{*}{ Astringency } & I & $N_{5}$ & 4.8 & 9.51 & & $N_{5}$ & 4.8 & 9.46 & \\
\hline & II & 73 & 4.1 & 1.46 & $2.0-8.0$ & 20 & 4.1 & 1.52 & $2.7-8.0$ \\
\hline \multirow{2}{*}{ Fruity } & I & 107 & 3.3 & 2.04 & $0.3-8.9$ & 60 & 3.4 & 1.90 & $0.5-8.0$ \\
\hline & II & 113 & 2.9 & 1.38 & $0.3-5.5$ & 36 & 2.4 & 1.38 & $0.5-5.6$ \\
\hline
\end{tabular}

Negative

\begin{tabular}{|c|c|c|c|c|c|c|c|c|c|}
\hline \multirow{2}{*}{ Bitterness } & I & 107 & 1.6 & 0.69 & $0.4-5.3$ & 60 & 1.7 & 0.88 & $0.3-5.7$ \\
\hline & II & 110 & 1.6 & 0.90 & $0.3-5.7$ & 37 & 1.7 & 1.02 & $0.5-5.7$ \\
\hline \multirow{2}{*}{ Unclean } & I & 64 & 0.7 & 0.64 & $0.0-3.1$ & 37 & 0.9 & 0.74 & $0.0-3.1$ \\
\hline & II & 89 & 0.8 & 0.59 & $0.2-3.1$ & 22 & 0.9 & 0.61 & $0.2-2.8$ \\
\hline \multirow{2}{*}{ Oxidation } & I & 59 & 0.8 & 0.55 & $0.0-2.9$ & 28 & 0.5 & 0.53 & $0.0-2.1$ \\
\hline & II & 93 & 0.7 & 0.60 & $0.0-2.9$ & 20 & 0.6 & 0.67 & $0.0-2.1$ \\
\hline \multirow{2}{*}{ Ethyl acetate } & I & 75 & 0.7 & 0.62 & $0.2-4.7$ & 37 & 0.7 & 0.77 & $0.2-4.7$ \\
\hline & II & 95 & 0.7 & 0.71 & $0.2-4.7$ & 23 & 0.6 & 0.41 & $0.2-1.4$ \\
\hline
\end{tabular}

\section{Table 4}

Population statistics from the calibration and validation sets of white wines of the season I and II

\begin{tabular}{|c|c|c|c|c|c|c|c|c|c|}
\hline \multirow{2}{*}{ Attributes } & \multirow{2}{*}{ Set } & \multicolumn{4}{|c|}{ Calibration } & \multicolumn{4}{|c|}{ Validation } \\
\hline & & $N$ & $\bar{x}$ & $\sigma$ & Range & $N$ & $\bar{x}$ & $\sigma$ & Range \\
\hline \multicolumn{10}{|l|}{ Positive } \\
\hline Tone & I & 49 & 5.8 & 1.95 & $1.7-9.0$ & 12 & 5.8 & 1.82 & $2.8-8.7$ \\
\hline Color intensity & I & 48 & 7.1 & 1.06 & $4.2-8.7$ & 11 & 7.2 & 0.98 & $5.8-8.6$ \\
\hline Tropical fruity & I & 48 & 3.1 & 1.53 & $1.0-6.2$ & 13 & 2.7 & 1.44 & $1.3-6.0$ \\
\hline \multirow{2}{*}{ Citrus fruity } & I & 47 & 2.5 & 0.81 & $1.0-4.4$ & 12 & 2.6 & 0.70 & $1.4-3.6$ \\
\hline & II & 73 & 2.5 & 0.94 & $0.6-4.7$ & 45 & 2.4 & 0.95 & $0.7-4.2$ \\
\hline Acidity & II & 62 & 5.7 & 0.45 & $4.9-7.0$ & 45 & 5.6 & 0.62 & $4.5-8.0$ \\
\hline Bitterness & II & 49 & 1.5 & 0.42 & $0.6-2.2$ & 44 & 1.39 & 0.55 & $0.4-2.7$ \\
\hline
\end{tabular}




\begin{tabular}{|c|c|c|c|c|c|c|c|c|c|}
\hline Pleasantness & II & $\begin{array}{l}71 \\
\text { Ca }\end{array}$ & brati & 0.71 & $4.1-8.0$ & Val & dation & 0.80 & $4.2-8.1$ \\
\hline Atstrithyters $y$ & Set & $\begin{array}{l}72 \\
\boldsymbol{N}\end{array}$ & 1.4 & $\begin{array}{l}0.64 \\
\sigma\end{array}$ & $\begin{array}{l}0.2-3.8 \\
\text { Range }\end{array}$ & $\begin{array}{l}45 \\
N\end{array}$ & 1.4 & $\begin{array}{l}0.69 \\
\sigma\end{array}$ & $\begin{array}{l}0.5-3.7 \\
\text { Range }\end{array}$ \\
\hline Balance & II & 58 & 5.6 & 0.66 & $3.3-6.6$ & 45 & 5.6 & 0.93 & $3.0-7.6$ \\
\hline Negative & & & & & & & & & \\
\hline Herbaceous & I & 48 & 1.6 & 0.63 & $1.0-3.4$ & 12 & 1.7 & 0.87 & $1.0-3.6$ \\
\hline Ethyl acetate & II & 77 & 0.8 & 0.36 & $0.2-1.6$ & 45 & 0.8 & 0.39 & $0.2-1.6$ \\
\hline Acetic acid & II & 68 & 0.9 & 0.31 & $0.2-1.3$ & 43 & 0.8 & 0.34 & $0.1-1.2$ \\
\hline Oxidation & II & 68 & 0.9 & 0.39 & $0.2-1.9$ & 43 & 0.9 & 0.45 & $0.2-1.8$ \\
\hline Yeast & II & 61 & 1.0 & 0.31 & $0.2-1.7$ & 43 & 0.8 & 0.35 & $0.2-1.5$ \\
\hline Reduction & II & 40 & 0.9 & 0.37 & $0.2-1.7$ & 45 & 0.9 & 0.54 & $0.2-3.3$ \\
\hline
\end{tabular}

A trend in the tasting panel for assessing the intensity of the attributes or defects with fixed and repetitive values, such as $0,1,2$ or intermediate points, was observed. This panel trend was detected for all the attributes and defects, despite that the rating scales are continuous. This was noted in varying degrees in the different calibration and validation graphics which are shown below (Figs. 3, 4, $5,6,7,8)$. Some samples with repetitive reference values from the calibrations and validations were separated by this reason. Besides, it was observed that some of the analyzed wines were not suitable for the calibrating or validating of some attributes or defects. This is why the calibration and validation sets for the different attributes and defects show different sizes.

\section{Spectra acquisition and chemometrics}

Examples of the Vis/NIR transmittance spectra registered from red and white wines are shown in Fig. 1. The differences between spectra from both wine types are clearly highlighted. This was due mainly to higher transmittance in the visible wavelengths in the white wines. In addition, the wavelengths from 400 to $500 \mathrm{~nm}$ show some small differences among the red wines probably due to some unidentified compounds, which are not in the spectra from the white wines.

\section{Fig. 1}

Examples of red and white wines spectra 


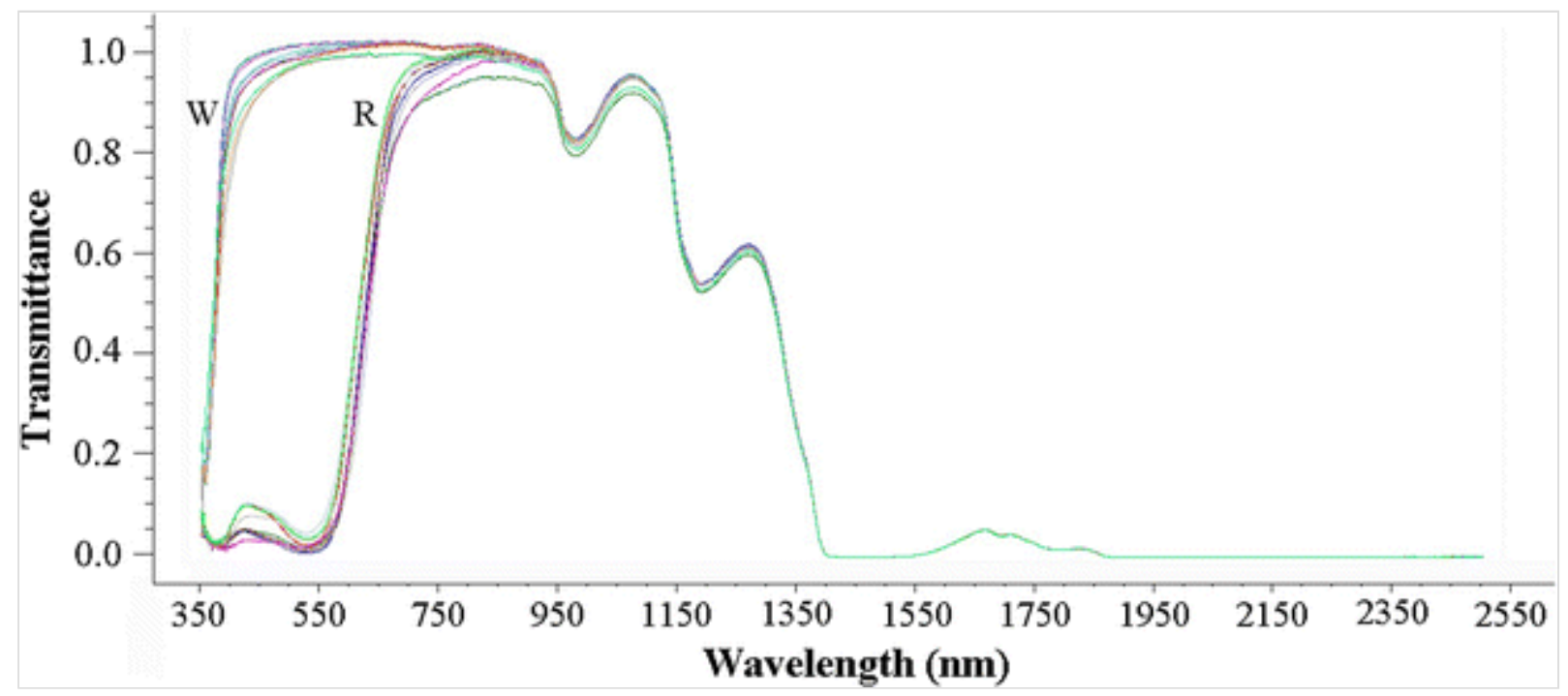

The data pre-treatment which generally provided the best outcome was transformation to absorbance, followed by mean normalization and SavitzkyGolay first derivative, with 0 smoothing points, left-side points 1, right-side points 1 and polynomial order 1 .

Some examples of the wavelength selection for model development from the spectra Vis/NIR are shown for the sensory attributes Persistency (Fig. 2 a) of red wines, and Fruity (Fig. 2b), and for the defect Oxidation (Fig. 2c). These graphs depict the final regression coefficients, after the wavelengths exclusion procedure. As can be observed, the Persistency model involves more wavelengths than the models Fruity and Oxidation, what may be due to the higher chemical complexity of the Persistency attribute.

\section{Fig. 2}

Wavelengths contributing to Persistent, Fruity and Oxidized of red wines 


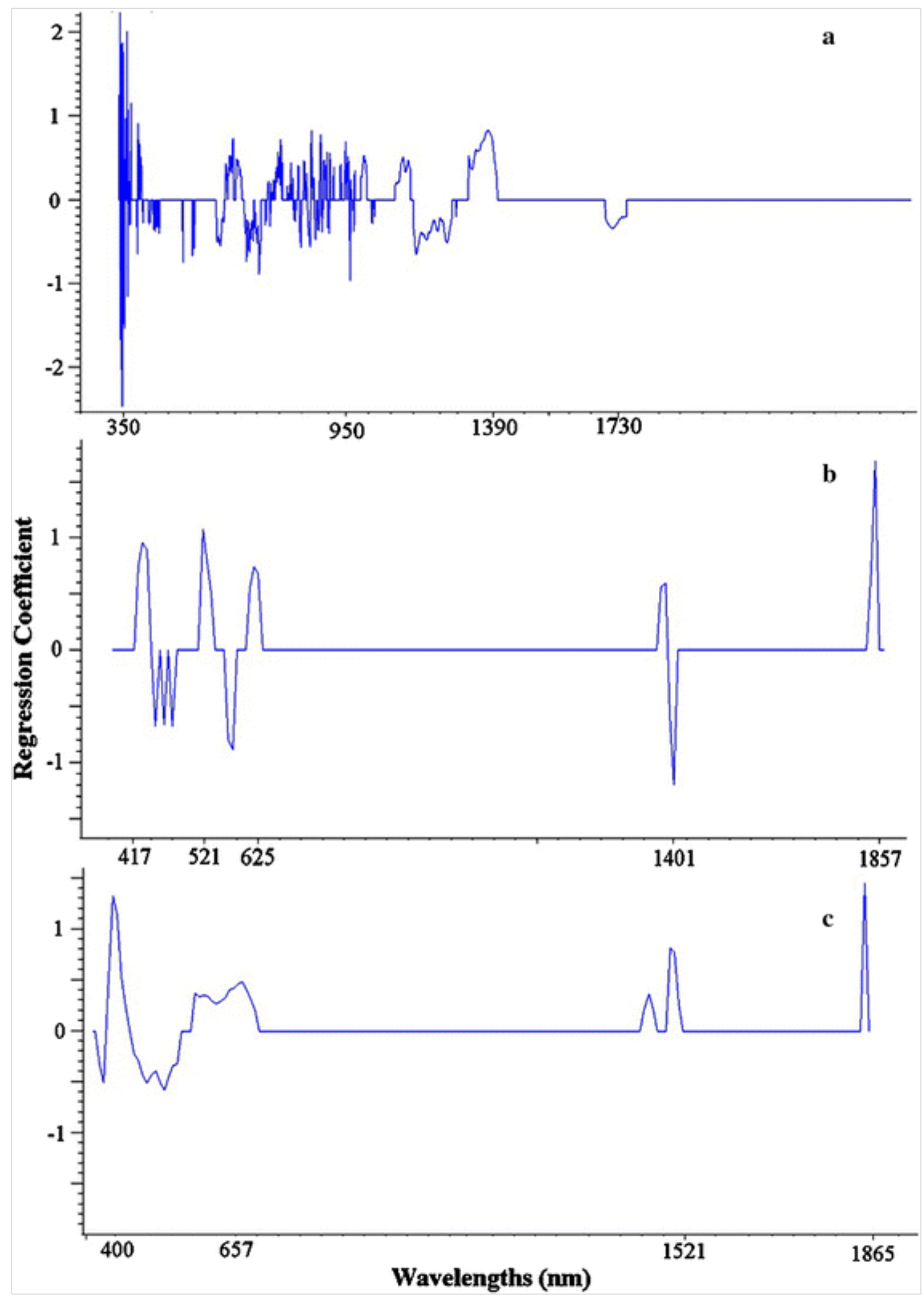

\section{Predicting sensory attributes of red wines}

The statistics of the calibrations of the sensory attributes and defects of red wines built from the two different seasons are shown in Table 5. The calibration models Flavor intensity and Astringency are shown in Figs. $3 \mathrm{a}$ and $4 \mathrm{a}$.

\section{Table 5}

Statistical coefficients of models for predicting sensory attributes of red wines 


\begin{tabular}{|c|c|c|c|c|c|c|c|c|c|}
\hline \multirow{2}{*}{ Attributes } & \multirow{2}{*}{ Set } & \multicolumn{4}{|c|}{ Calibrations } & \multicolumn{4}{|c|}{ Validations } \\
\hline & & $N$ & PC & $R_{\mathrm{c}}$ & $R_{\mathrm{CV}}$ & SEC & $N$ & $R$ & RPD \\
\hline \multirow{3}{*}{$\begin{array}{l}\text { Positive } \\
\text { Attributes } \\
\text { Flavor intensity }\end{array}$} & \multirow{2}{*}{$\begin{array}{l}\text { Set } \\
\text { I }\end{array}$} & \multicolumn{4}{|c|}{ Calibrations } & \multicolumn{4}{|c|}{ Validations } \\
\hline & & 92 & PC & 6.97 & R.92 & S!EC & 22 & 8.90 & RBD \\
\hline & II & 115 & 10 & 0.85 & 0.72 & 0.96 & 36 & 0.87 & 2.00 \\
\hline \multirow{2}{*}{ Color intensity } & I & 90 & 4 & 0.90 & 0.88 & 0.49 & 21 & 0.92 & 2.54 \\
\hline & II & 111 & 4 & 0.87 & 0.86 & 0.49 & 39 & 0.88 & 2.12 \\
\hline \multirow{2}{*}{ Length } & I & 93 & 7 & 0.91 & 0.85 & 0.33 & 22 & 0.90 & 2.16 \\
\hline & II & 110 & 9 & 0.89 & 0.81 & 0.34 & 60 & 0.80 & 1.65 \\
\hline \multirow{2}{*}{ Persistency } & I & 90 & 5 & 0.83 & 0.78 & 0.51 & 22 & 0.84 & 1.78 \\
\hline & II & 115 & 7 & 0.85 & 0.77 & 0.44 & 38 & 0.87 & 2.04 \\
\hline \multirow{2}{*}{ Astringency } & I & 45 & 4 & 0.90 & 0.85 & 0.64 & 15 & 0.92 & 2.52 \\
\hline & II & 73 & 5 & 0.86 & 0.83 & 0.75 & 20 & 0.89 & 2.13 \\
\hline \multirow{2}{*}{ Fruity } & I & 107 & 6 & 0.90 & 0.88 & 0.87 & 60 & 0.73 & 1.49 \\
\hline & II & 113 & 8 & 0.85 & 0.77 & 0.72 & 36 & 0.77 & 1.55 \\
\hline \multirow{2}{*}{ Bitterness } & I & 107 & 10 & 0.84 & 0.76 & 0.38 & 60 & 0.64 & 1.30 \\
\hline & II & 110 & 10 & 0.87 & 0.75 & 0.44 & 37 & 0.84 & 1.82 \\
\hline
\end{tabular}

Negative

\begin{tabular}{|l|l|l|l|l|l|l|l|l|l|}
\hline \multirow{3}{*}{ Oxidation } & I & 59 & 5 & 0.94 & 0.92 & 0.18 & 35 & 0.89 & 2.04 \\
\hline \multirow{2}{*}{ Unclean } & II & 93 & 10 & 0.97 & 0.92 & 0.14 & 20 & 0.93 & 2.77 \\
\hline \multirow{2}{*}{ Ethyl acetate } & I & 64 & 5 & 0.94 & 0.93 & 0.21 & 37 & 0.89 & 2.05 \\
\hline & II & 89 & 2 & 0.86 & 0.80 & 0.31 & 22 & 0.78 & 1.61 \\
\hline & I & 75 & 7 & 0.90 & 0.73 & 0.27 & 37 & 0.82 & 1.71 \\
\hline & II & 95 & 10 & 0.92 & 0.78 & 0.29 & 23 & 0.88 & 1.36 \\
\hline
\end{tabular}

$N$ size of the samples set, $P C$ number of principal components, $R_{\mathrm{c}}$ coefficient of calibration, $R_{\mathrm{CV}}$ coefficient of cross-validation, $S E C$ standard error of calibration, $R P D$ residual predictive deviation, $r$ coefficient of correlation between the values analyzed and predicted

Fig. 3

Flavor intensity of red wines. Calibration (a) and validation (b). 

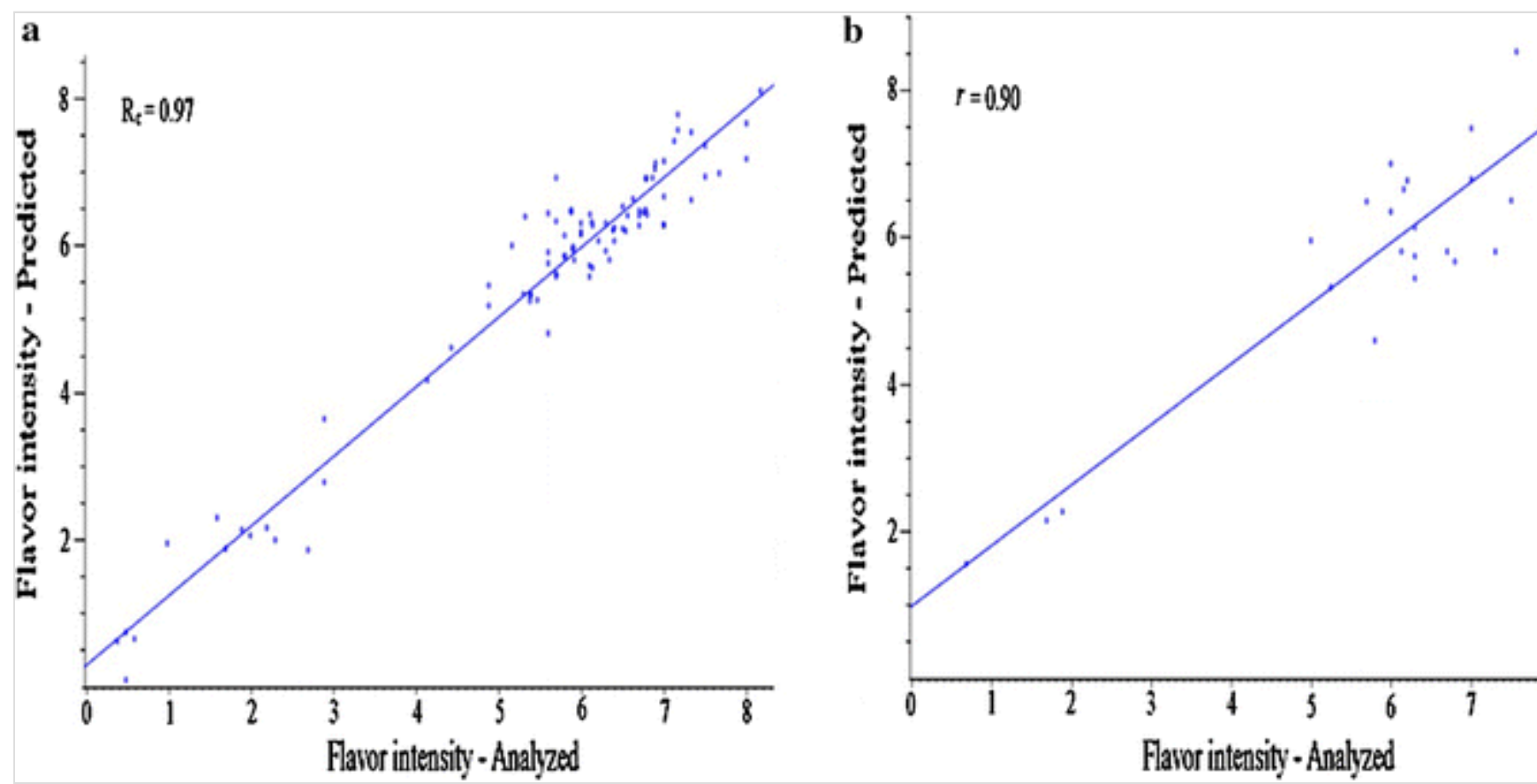

Fig. 4

Astringency of red wines. Calibration (a) and validation (b).
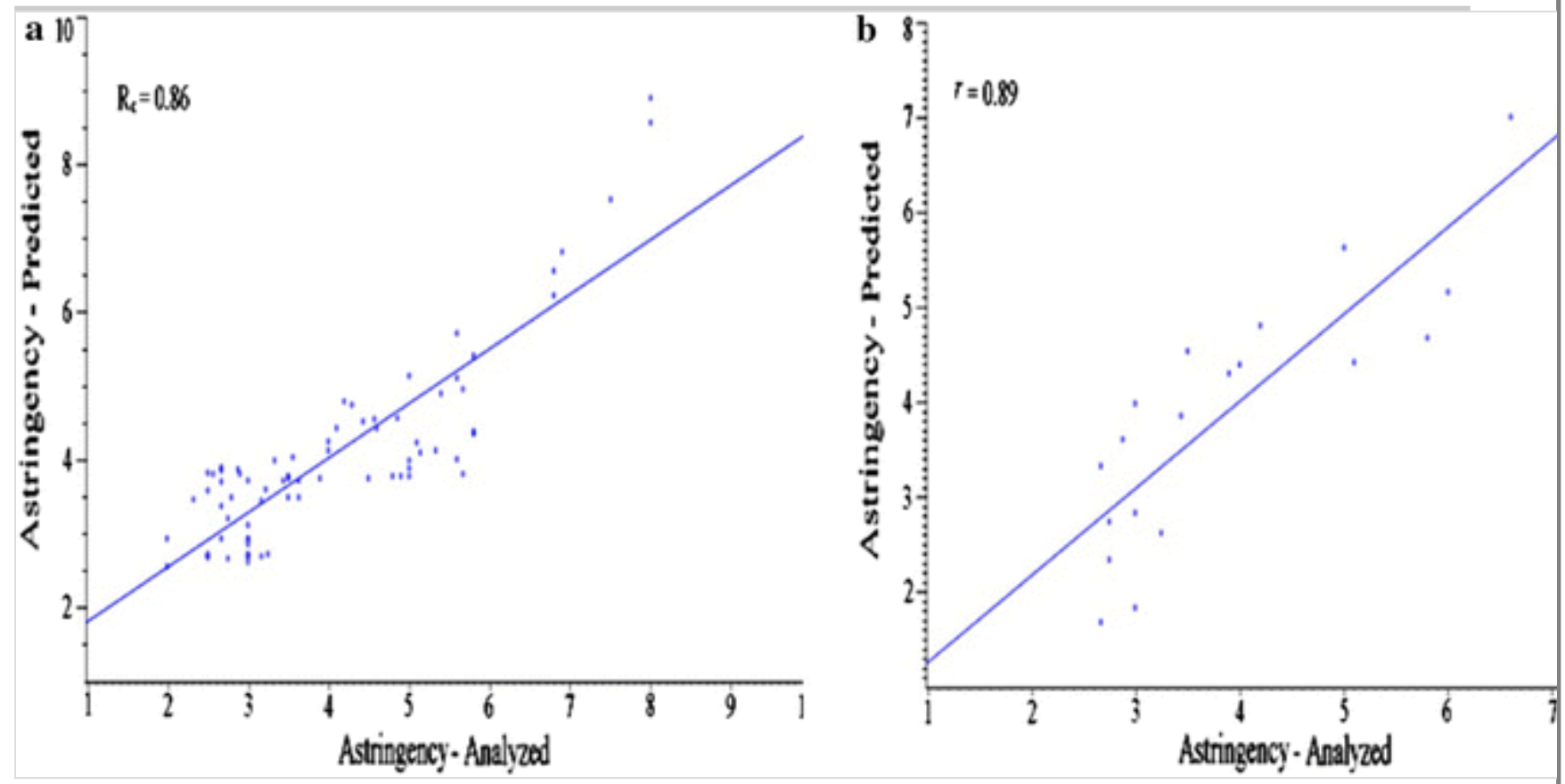

The predicting tests using the red wine models in external validation exercises showed consistent results with the calibration statistics. Thus, Color intensity, Flavor intensity and Astringency were highlighted. These last two are depicted in Figs. $3 \mathrm{~b}$ and $4 \mathrm{~b}$. Their $r$ was 0.90 and 0.89 , while the RPD was 2.33 and 2.13. In the same way, the validations for Color intensity, Length, Persistency and Fruity provided $r$ values $0.92,0.90,0.87$ and 0.77 , and always referred to the best validation carried out for each attribute from both seasons. The statistical indicators of these validation tests are included in Table 5. 
The statistics of the calibrations built for predicting red wine defects are shown in Table 5. The calibration model Oxidation with $R_{\mathrm{C}} 0.94$ and $R_{\mathrm{CV}} 0.92$ is shown in Fig. 5 a.

Fig. 5

Oxidation of red wines. Calibration (a) and validation (b).
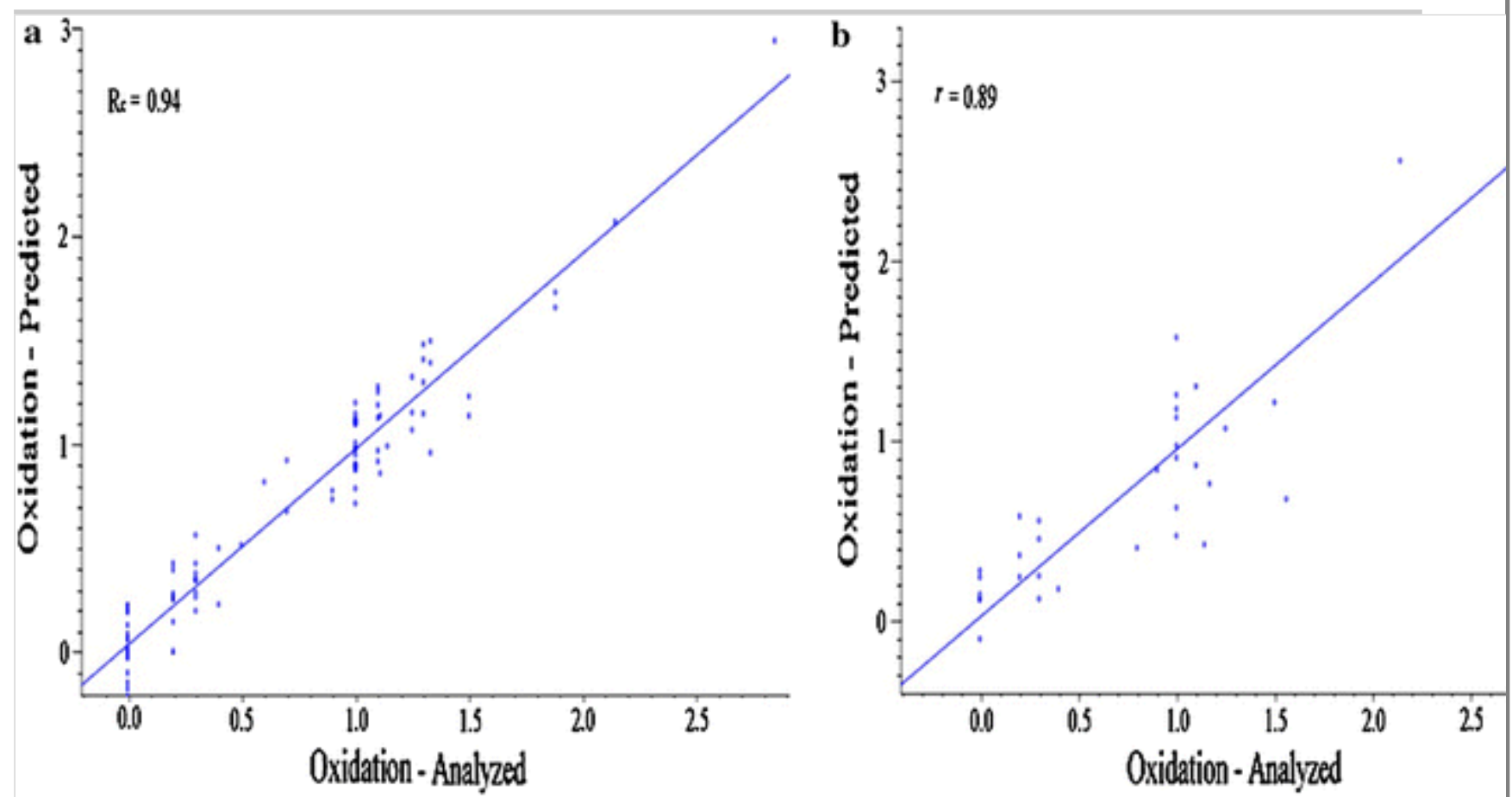

The exercises with the models for predicting Oxidation defect in red wines gave $r 0.89$ and 0.93 and RPD 2.04 and 2.77, respectively, for external validations I and II. These statistics are shown in Table 6. The exercise I, with the higher N for validating this defect, is shown in Fig. $5 \mathrm{~b}$. For the Unclean defect, the $r$ values from the validation tests corresponding to seasons I and II were 0.89 and 0.78 , and RPD 2.05 and 1.61 .

\section{Table 6}

Statistical coefficients of models for predicting sensory attributes of white wines

\begin{tabular}{|l|l|l|l|l|l|l|l|l|l}
\hline \multirow{3}{*}{ Attributes } & \multirow{3}{*}{ Season } & \multicolumn{3}{l}{ Calibration } & \multicolumn{3}{l}{ Validation } \\
\cline { 3 - 9 } & & $N$ & PC & $R_{\mathrm{c}}$ & $R_{\mathrm{CV}}$ & SEC & $N$ & $R$ & RPD
\end{tabular}

Positive

\begin{tabular}{|l|l|l|l|l|l|l|l|l|l|}
\hline Tone & I & 49 & 10 & 0.97 & 0.89 & 0.45 & 12 & 0.83 & 1.78 \\
\hline Color intensity & I & 48 & 5 & 0.91 & 0.79 & 0.43 & 11 & 0.82 & 1.63 \\
\hline Tropical fruity & I & 48 & 5 & 0.91 & 0.82 & 0.61 & 13 & 0.77 & 1.55 \\
\hline Pleasantness & II & 71 & 10 & 0.90 & 0.84 & 0.31 & 45 & 0.73 & 1.46 \\
\hline
\end{tabular}




\begin{tabular}{|c|c|c|c|c|c|c|c|c|c|}
\hline \multirow[b]{2}{*}{ Atetribaresy } & \multirow[b]{2}{*}{ Season } & \multicolumn{4}{|c|}{ Calibration } & \multirow{2}{*}{\multicolumn{2}{|c|}{ Validation }} & \multirow[b]{2}{*}{0.65} & \multirow[b]{2}{*}{1.26} \\
\hline & & 72 & 10 & 0.85 & 0.79 & & & & \\
\hline Balance & II & 58 & $8 \mathrm{C}$ & $\begin{array}{l}\boldsymbol{R}_{0.87} \\
0.87\end{array}$ & $\begin{array}{l}R \\
0.77\end{array}$ & SEC & $N_{5}$ & $R_{0.65}$ & RPD \\
\hline Acidity & II & 62 & 10 & 0.91 & 0.88 & 0.19 & 45 & 0.62 & 1.27 \\
\hline Bitterness & II & 49 & 10 & 0.94 & 0.92 & 0.14 & 44 & 0.65 & 1.21 \\
\hline \multirow{2}{*}{ Citrus fruity } & I & 47 & 6 & 0.93 & 0.77 & 0.29 & 12 & 0.71 & 1.41 \\
\hline & II & 73 & 5 & 0.86 & 0.83 & 0.48 & 45 & 0.63 & 1.14 \\
\hline \multicolumn{10}{|l|}{ Negative } \\
\hline Herbaceous & I & 48 & 4 & 0.89 & 0.80 & 0.28 & 12 & 0.66 & 1.32 \\
\hline Ethyl Acetate & II & 77 & 10 & 0.97 & 0.95 & 0.09 & 45 & 0.92 & 2.54 \\
\hline Acetic Acid & II & 68 & 10 & 0.98 & 0.98 & 0.05 & 43 & 0.91 & 2.37 \\
\hline Oxidation & II & 67 & 10 & 0.96 & 0.87 & 0.11 & 43 & 0.89 & 2.18 \\
\hline Yeast & II & 61 & 4 & 0.88 & 0.86 & 0.15 & 43 & 0.68 & 1.36 \\
\hline Reduction & II & 40 & 7 & 0.96 & 0.95 & 0.10 & 45 & 0.65 & 1.32 \\
\hline
\end{tabular}

$I$ season I, $I I$ season II, $N$ size of the samples set, $P C$ number of principal components, $R_{\mathrm{c}}$ coefficient of calibration, $R_{\mathrm{CV}}$ coefficient of cross-validation, $S E C$ standard error of calibration, $R P D$ residual predictive deviation, $r$ coefficient of correlation between the values analyzed and predicted

\section{Predicting sensory attributes of white wines}

The tests with white wines in the first season provided good results for a group of attributes and defects. The study highlighted the predictive models for the visual attributes, Tone and Color intensity, with $R_{\mathrm{C}} 0.97$ and 0.91 , and $R_{\mathrm{CV}} 0.89$ and 0.79 . These statistics are shown in Table 6 . Their external validation exercises provided $r 0.83$ and 0.82 . Similar calibration statistics were obtained for the attributes Tropical fruit and Citrus fruit, showing $R_{\mathrm{C}} 0.91$ and 0.93 , and $R_{\mathrm{CV}} 0.82$ and 0.77 . Their validations provided $r 0.77$ and 0.71 . For the sensory defect Herbaceous, $R_{\mathrm{C}} 0.89$ and $R_{\mathrm{CV}} 0.80$ were determined and the validation $r$ was 0.66 .

Considering those results, new calibration tests were carried out in the following season with a larger set of white wines. They were distributed in calibration and validation sets composed by 77 and 45 samples, from which some samples with reference values repetitive were separated. Their statistics are shown in Table 6 . The predictive models Ethyl acetate, Acetic acid and Oxidation provided $R_{\mathrm{C}}$ 
0.97, 0.98 and 0.96 , and $R_{\mathrm{CV}} 0.90,0.98$ and 0.87 , which are shown in Figs. 6 a, $7 \mathrm{a}$ and $8 \mathrm{a}$. The external validation exercises with these calibrations are depicted in Figs. 6b, $7 \mathrm{~b}$ and $8 \mathrm{~b}$, and provided $r 0.92,0.91$ and 0.89 .

Fig. 6

Ethyl acetate of white wine. Calibration (a) and validation (b).
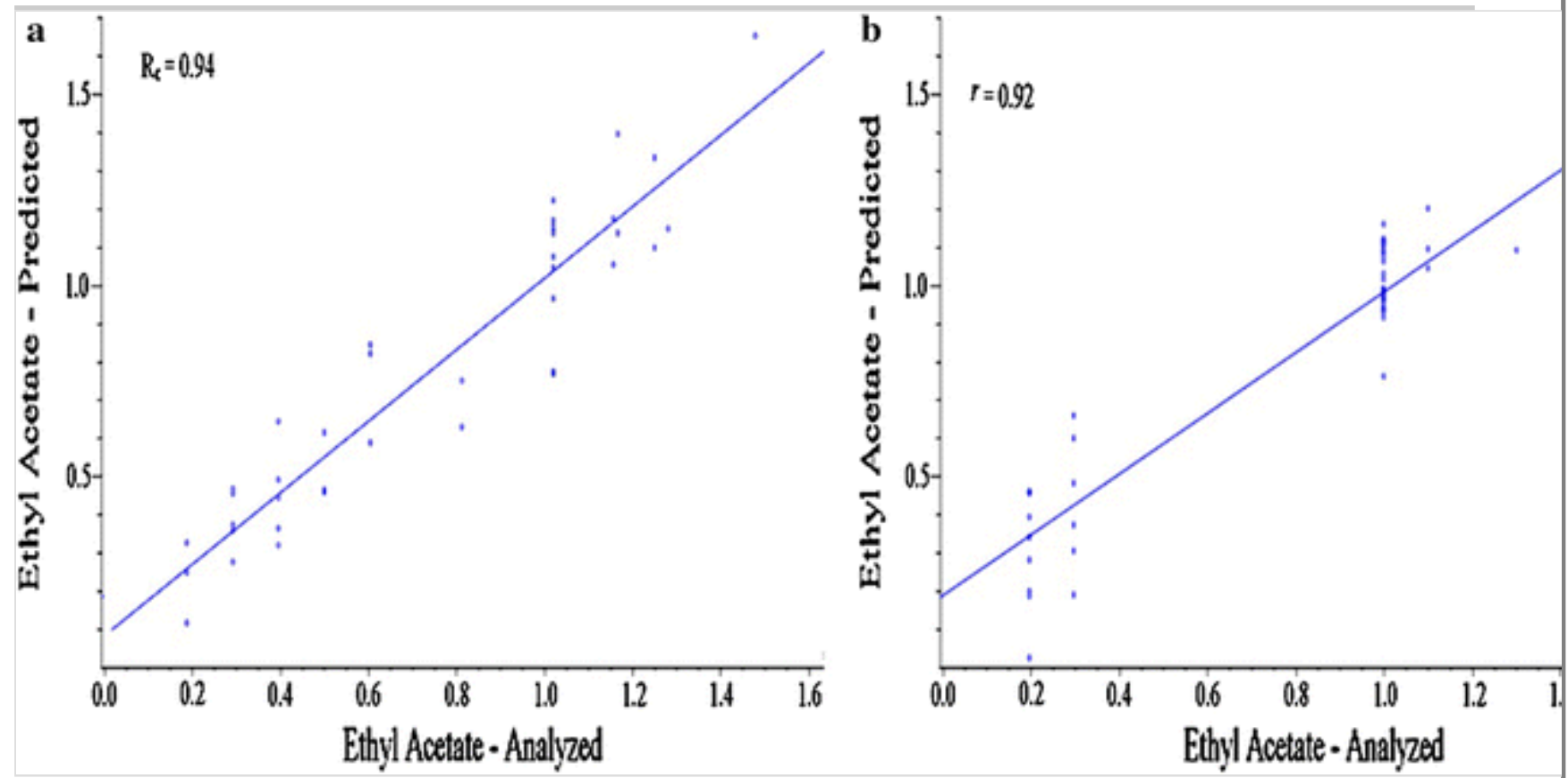

Fig. 7

Acetic acid of white wines. Calibration (a) and validation (b).
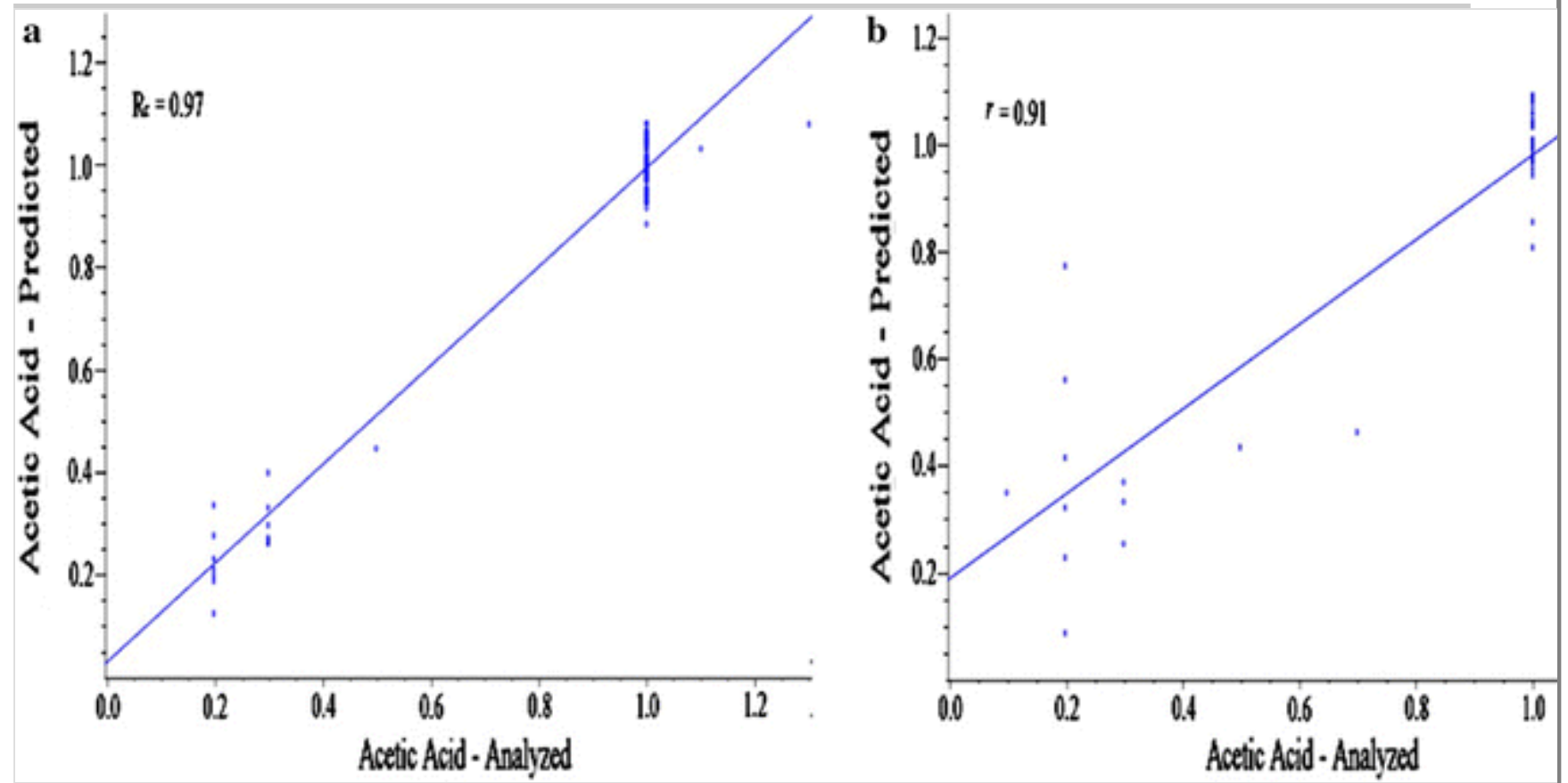

Fig. 8

Oxidation of white wines. Calibration (a) and validation (b). 

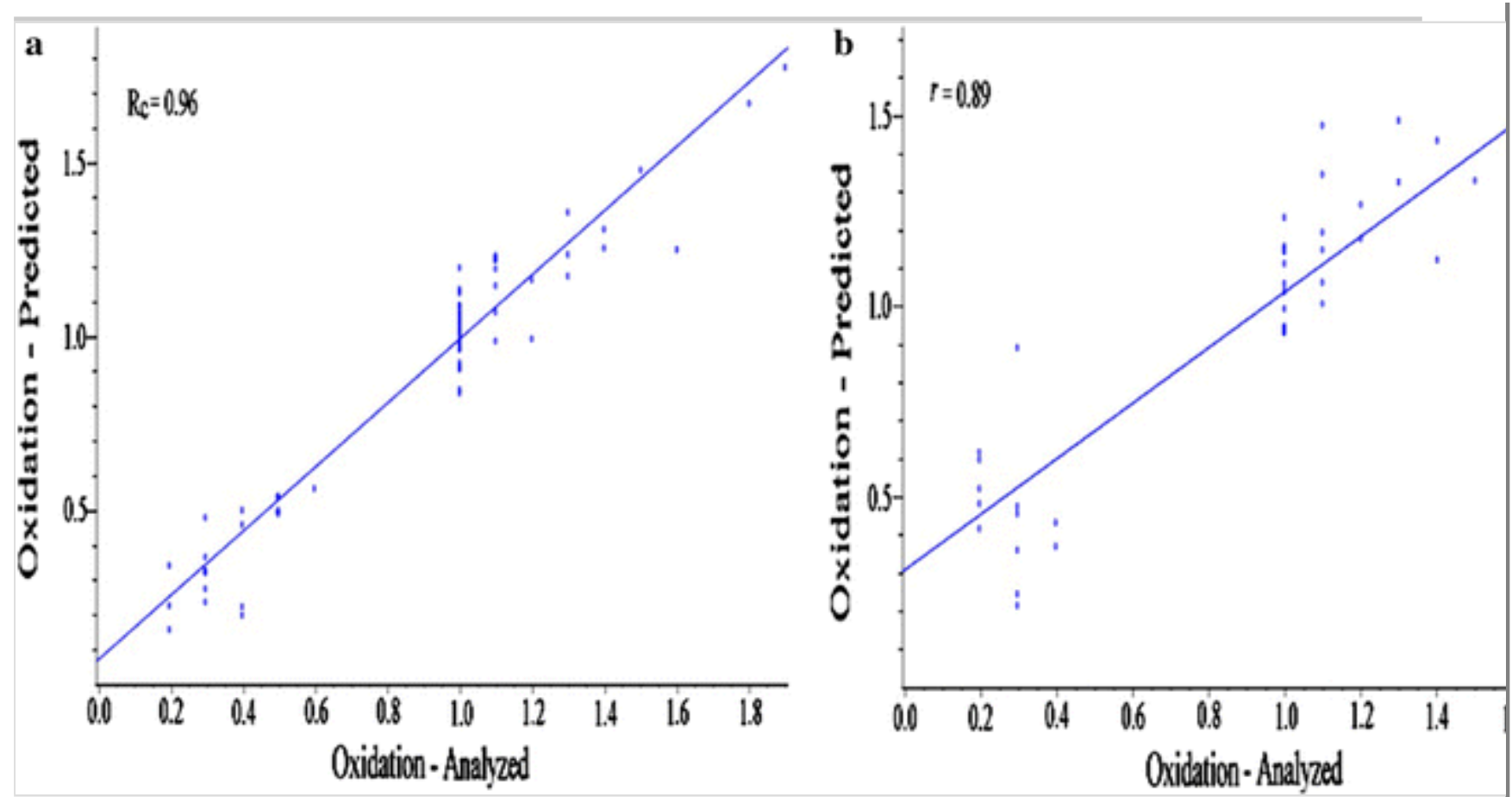

Other models for some sensory attributes of the white wine group of the second season showed good predictive potential as well. Pleasantness, Balance, Astringency and Citrus fruit gave $R_{\mathrm{C}} 0.90,0.85,0.87$, and 0.86 and $R_{\mathrm{CV}} 0.84$, $0.79,0.77$ and 0.83 . Their validation showed $r 0.73,0.65,0.65$ and 0.63 .

\section{Discussion}

\section{Sensory analysis}

The trend of the tasting panel for assessing the intensity of the attributes or defects with repetitive fixed values reveals a limit of the panel sensitivity for their accurate assessment. Therefore, it is reasonable to think, a priori, that in such cases the prediction given by the calibration is better than the panel assessment. In this sense, a method was reported for determining when NIR is better than a reference method [27]. This method requires circulating and analyzing $N$ samples using the same analytical method at different locations with different operators, although this is beyond the scope of this study.

\section{Predicting sensory attributes of red wines}

The statistics of the calibrations of red wines from the two different seasons are in agreement, which confirms their performance features. The calibrations for the attributes Color intensity, Flavor intensity and Astringency show $R_{\mathrm{C}} 0.90$, 0.97 and 0.90 , while $R_{\mathrm{CV}}$ were $0.88,0.92$ and 0.85 , and can be highlighted for their accuracy. The calibrations for Persistency and Fruity, despite showing slightly lower coefficients $R_{\mathrm{CV}}$, still provided good predictive potential. 
Regarding the predicting tests statistics, it is important to bear in mind that the use of RPD assumes that the errors of the reference method are negligible [27]. That is not the case with a sensory analysis. However, it should be remembered that RPD is essentially the same statistic $r$ [26]. Nevertheless, it is normally used for assessing NIR models, since it aids in interpreting the calibration performance. According to several authors [28, 29, 30, 31], RPD values between 2 and 10 reflect that model's predictive aptness depending on the use it must provide. The prediction exercises carried out highlighted the models for the attributes Astringency, Flavor intensity, Length and Persistency in red wines, and the best external validations gave RPD 2.52, 2.33, 2.16, and 2.04. Considering these statistics, they can be considered useful for contrasting or confirming the assessments of the wines obtained by the sensory analysis.

Regarding red wine defects, Oxidation and Unclean showed the most closeness between the $R_{\mathrm{c}}$ and $R_{\mathrm{CV}}$ values, revealing their good accuracy. Ethyl acetate and Bitterness showed good predictive potential, although the differences between the same statistics were slightly higher. This technique is suitable to predict the defect Oxidation in red wines. Exercise I, with the higher $\mathrm{N}$ for validating this defect, is shown in Fig. $5 b$. For the Unclean defect, the $r$ values from the validation tests I and II were 0.89 and 0.78 , and RPD 2.05 and 1.61. According to these data, the test I for Unclean was satisfactory. It was carried out with a larger validation set than test II, despite the fact that calibration set II was larger than that for I.

\section{Predicting sensory attributes of white wines}

The predictive models of white wine defects from the second season were generally better than those for positive attributes. The statistics, shown in Table 6 , highlighted their good predictive ability. The calibrations of the sensory defects Reduction, Bitterness, Yeast and Acidity showed interesting predictive potential although their performance in the validation tests was lower than expected.

The ethyl acetate, acetic acid and oxidation sensory defects are not specific to a type of white wine. Therefore, the results obtained with these from wines of different types were better than models for other more specific attributes or defects of wine types. The absence of defects in white wines is an essential factor for quality. Hence, the interest of the results from this study. In addition, it is important to consider that new calibrations for specific white wine types could improve the present results for positive attributes or defects which are specific to certain white wines. 


\section{Conclusions}

This research showed that the Vis/NIR technique was feasible for predicting some of the most important sensory attributes of red wines in study, such as Flavor intensity, Astringency, Color intensity, Length and Persistency. The technique was also suitable for predicting some important defects of red wines, such as Oxidation and Unclean, and showed good aptitude for Ethyl acetate and Bitterness.

The test carried out with white wines, which was smaller, highlighted a good predictive potential particularly for the white wine defects Ethyl acetate, Acetic acid and Oxidation. The good predictive potential for the white wine sensory attributes Pleasantness, Balance, Astringency and Citrus fruit was also pointed out.

The main use of this technology could be to contrast or confirm the assessments of the wines obtained by the sensory analysis with tasting panels. It is reasonable to consider the possibility of tuning up the technique for detecting some defects in routine analyses. The technique was developed for a specific spectrometer Vis/NIR, thus a calibration and a periodic validation procedure are necessary to adapt it to different instruments.

\section{References}

1. Vannier A, Bruna OX, Feinberg MH (1999) Application of sensory analysis to champagne wine characterisation and discrimination. Food Qual Prefer 10:101-107

2. Cozzolino D, Smith HE, Lattey KA, Cynkar W, Janik L, Dambergs RG, Francis IL, Gishen M (2006) Combining mass spectrometry based electronic nose, visible-near infrared spectroscopy and chemometrics to assess the sensory properties of Australian Riesling wines. Anal Chim Acta 563:319324

3. Tempere S, Hamtat ML, Bougeant JC, de Revel GM, Sicard G (2014) Learning odors: the impact of visual and olfactory mental imagery training on odor perception. J Sens Stud 29:435-449

4. Vidal L, Antúnez L, Giménez A, Ares G (2016) Evaluation of palate cleansers for astringency evaluation of red wines. J Sens Stud 31:93-100 
5. Le Cloirec P, Gueux M, Paillard H, Anselme C (1991) In: Martin G, Laport P (eds) Odeurs and desodorisation dans l'Environnement. Cachan, Lavoisier

6. Berglund B, Berglund U, Lindwall T, Svensson LT (1973) A quantitative principle of perceived intensity summation in odours mixtures. J Exp Psychol 100:29-38

7. Forina M, Oliveri P, Bagnasco L, Simonetti R, Casolino MC, Nizzi Grifi F, Casale M (2015) Artificial nose, NIR and UV-visible spectroscopy for the characterisation of the PDO Chianti Classico olive oil. Talanta 144:10701078

8. Downey G, Sheehan E, Delahunty C, Callaghan O, Guinee T, Howard V (2005) Prediction of maturity and sensory attributes of Cheddar cheese using near-infrared spectroscopy. Int Dairy J 15:701-709

9. Woodcock T, Fagan C, O’Donell C, Downey G (2008) Application of near and mid-infrared spectroscopy to determine cheese quality and authenticity. Food Bioprocess Technol 1(2):117-129

10. Cattaneo TMP, Tornelli C, Erini S, Panarelli EV (2008) Relationship between sensory scores and near infrared absorptions in characterising Bitto, an Italian protected denomination of origin cheese. J NIRS 16:173-178

11. Meulemans A, Dotreppe O, Leroy B, Istase L, Clinquart A (2003) Prediction of organoleptic and technological characteristics of pork meat by near infrared spectroscopy. Sci Aliment 23:159-162

12. Andrés S, Murray I, Navajas EA, Fisher AV, Lambe NR, Bünger L (2007) Prediction of sensory characteristics of lamb meat samples by near infrared reflectance spectroscopy. Meat Sci 76:509-516

13. Ripoll G, Albertí P, Panea B, Olleta JL, Sañudo S (2008) Near-infrared reflectance spectroscopy for predicting chemical, instrumental and sensory quality of beef. Meat Sci 80:697-702

\section{Ortiz MC, Sarabia L, García-Rey R, Luque de Castro MD (2006)}

Sensitivity and specificity of PLS-class modelling for five sensory characteristics of dry-cured ham using visible and near infrared spectroscopy. Anal Chim Acta 558:125-131 
15. Harker FR, Marsh KB, Young H, Murray SH, Gunson FA, Walker SB (2002) Sensory interpretation of instrumental measurement. 2. Sweet and acid taste of apple fruit. Post Bioltechnol 24:241-250

16. Piers A, Desmet M, Nicolai B, Buyssens S (2003) Relations between sensory analysis, instrumental quality and NIR measurements of tomato quality. Acta Hortic 600:471-477

17. Francois I, Wins H, Buysens S, Godts C, Van Pee E, Nicoläi B, De Proft M (2008) Predicting sensory attributes of different chicory hybrids using physico-chemical measurements and visible/near infrared spectroscopy. Post Biol Technol 49:366-373

18. Yan SH (2005) Evaluation of the composition and sensory properties of tea using near infrared spectroscopy and principal component analysis. $\mathrm{J}$ NIRS 13:313-325

19. Cozzolino D, Smith HE, Lattey KA, Cynkar W, Janik L, Dambergs RG, Francis IL, Gishen M (2005) Relationship between sensory analysis and near infrared spectroscopy in Australian Riesling and Chardonnay wines. Anal Chim Acta 539:341-348

20. Cozzolino D, Cowey G, Lattey KA, Godden P, Cynkar W, Dambergs RG, Janik L, Gishen M (2008) Relationship between wine scores and visiblenear-infrared spectra of Australian red wines. Anal Bioanal Chem 391:975981

21. AENOR (1992) Análisis sensorial. Metodología. Método para establecer el perfil olfato-gustativo.

22. Nobel AC, Arnold RA, Masuda BM, Pecore SD, Schmidt JO, Sterm PM (1984) Progress towards a standardized system of wine aroma terminology. Am J Enol Vitic 35:42-52

23. Nobel AC, Arnold RA, Buechsenstein J, Leach EJ, Schmidt JO, Sterm PM (1987) Modification of a standardized system of wine aroma terminology. Am J Enol Vitic 38:143-146

24. Brown B, Aaron M (2001) In: Smith J (ed) The rise of modern genomics, 3rd edn. Wiley, New York 
25. Williams P, Sobering D (1996) In: Davies AMC, Williams P (eds) Near infrared spectroscopy: the future waves. NIR Publications, Chichester

26. Minasny B, McBratney A (2013) Why you don't need to use RPD. Pedometron 33:14-15

27. Andersson M, Nørgaard L. A procedure to determine when NIR is better than its reference method. NIR2013 Proceedings. 2013; P. 618-620.

28. Fearn T (2002) Assessing calibration: SEP, RPD, RER and $\mathrm{R}^{2}$. NIR News 13(6):12-14

29. Williams P (2014) The RPD statistic: a tutorial note. NIR News 25(1):22

30. Fearn T (2015) The library of Babel (validation). NIR News 26(8):23

31. Esbensen KH, Geladi P, Larsen A (2014) The RPD myth. NIR News 25(5):24 